\title{
THE HISTOCHEMISTRY OF COLLAGENS AND FIBRONECTIN IN THE GALLBLADDERS OF THE GUINEA PIG AND MOUSE
}

\author{
Kazuyori YAMADA, Yasumasa MATSUMURA, Haruki SUZUKi \\ AND OSAMu FUJIMORI \\ Department f Anatomy, Nagoya City University Medical School, Nagoya 467
}

Received for publication August 2, 1989 and in revised form October 12, 1989

\begin{abstract}
In the gallbladders of the guinea pig and mouse, the localizations and histochemical properties of certain connective tissue antigens were studied by means of indirect immunoperoxidase methods in light microscopy. These antigens were types I, III and IV collagens and fibronectin. The results obtained show that the four antigens exhibited such histochemical natures as are characteristic to each of them. The histophysiological significances of these antigens are discussed with special reference to the known physiological functions of the gallbladder to regulate biliary pressure throughout the bile drainage system of mammals.
\end{abstract}

One of the primary physiological functions performed by the mammalian gallbladders is to control the hydrostatic pressure of the bile running through the bile drainage system $(10,19,22)$. The mechanical architecture of the gallbladder is believed to be closely correlated with such a function. In mammalian gallbladders, an important mechanical architecture is known to consist of connective tissues involved in the lamina propria, tela submucosa, muscular coat and external layer of the organ $(10,19)$. However, little information is available as to the histochemistry of connective tissues involved in the walls of mammalian gallbladders, except for the pyroninophylia of elastic fibers in human gallbladders (19), neutral and acidic glycoproteins and proteoglycans of connective tissue cells, fibers and matrices in mammalian gallbladders (19), cholesterol of subepithelial connective tissues in human gallbladders (2) and IgA, IgM or IgG-containing cells in the mucous connective tissues of normal and inflamed human gallbladders (5).

In the present study, attempts have been made to investigate the histochemical localizations and properties of connective tissue antigens such as collagens and fibronectin in the gallbladders of two mammalian species (guinea pig and mouse). In view of the important physiological roles played by these functional proteins for the mechanical architecture of connective tissues $(6,7,14,15,20)$, the results obtained in the present study are thought to provide basic and important data, which are indispensable for thorough recognition of the control mechanism of hydrostatic pressure in the mammalian bile drainage system performed by the relevant gallbladders. 


\section{MATERIALS AND METHODS}

In the present study, 10 male adult guinea pigs (Hartley strain, 10 weeks in age) and 10 male adult mice (ddY strain, 8 weeks in age) were used. Under Nembutal anesthesia, the guinea pigs were sacrificed by perfusion with any one of the three fixatives (Bouin's solution, 100\% ethanol and 1\% acetic acid in 100\% ethanol), whereas the mice were killed by decapitation. In their intermediate states between contraction and dilatation, gallbladders were dissected out from the donor animals sacrificed as abowe, cut into cubes with a side of approximately $5 \mathrm{~mm}$ and then immersion-fixed in any one of the three fixatives mentioned above at $4^{\circ} \mathrm{C}$ or room temperature for $12-$ $24 \mathrm{hr}$. After fixation, the tissue specimens were dehydrated in an ethanol series of ascending concentrations, cleared in xylene and embedded in paraffin wax. On a sliding microtome, sections were cut at a thickness of $4 \mu \mathrm{m}$, affixed to glass slides without any adhesives, dried in an oven at $40^{\circ} \mathrm{C}$, dewaxed in xylene, hydrated through an ethanol series of descending concentrations and subjected to the following histological and immunohistochemical staining procedures.

(A) Histological staining procedure

For the observation of histological structures in general, a hemotoxylin-eosin (HE) staining procedure was used.

(B) Immunohistochemical staining procedures

For the immunohistochemical detection of connective tissue antigens, indirect immunoperoxidase methods $(8,9,21)$ for four antigens were employed. These antigens were type I collagen (C-I), type III collagen (C-III), type IV collagen (C-IV) and fibronectin (F).

As the first antibodies for the methods for C-I, C-III, C-IV and F, anti-rat C-I rabbit IgG, anti-bovine C-III rabbit IgG, anti-bovine C-IV rabbit IgG and antibovine F rabbit IgG (all from Advance Co. Ltd., Tokyo, Japan) were respectively used. The first three antibodies (for the methods for C-I, C-III and C-IV) were diluted 500 times for the guinea pig tissues and 1000 times for the mouse tissues respectively, whereas the last antibody (for the method for F) was uniformly diluted 1000 times for both the guinea pig and mouse tissues.

As the second antibodies for the four methods, horseradish peroxidase labelled anti-rabbit IgG antibody raised in goat (from Medical and Biological Laboratories Co. Ltd., Nagoya, Japan) was commonly employed at a dilution of 80 times.

In the four methods, the final reaction products were visualized by means of diaminobenzidine (DAB)-hydrogen peroxide $\left(\mathrm{H}_{2} \mathrm{O}_{2}\right)$ procedure (4). In the four staining methods, the first and second antibodies were reacted for 60 and $30 \mathrm{~min}$ respectively at room temperature, whereas the DAB- $\mathrm{H}_{2} \mathrm{O}_{2}$ procedure was performed for 3 to $5 \mathrm{~min}$ at the same temperature. Following the immunohistochemical stainings, all the tissue sections were counterstained with hematoxylin, so as to obtain the orientations of individual histologic structures. As controls for the four immunohistochemical staining procedures, some tissue sections were treated either with normal rabbit serum or with $0.01 \mathrm{M}$ phosphate buffered saline ( $\mathrm{pH} 7.4)$ (solvent of the first and second antibodies) instead of the first antibodies, prior to the subsequent stainings with the second antibodies and DAB- $\mathrm{H}_{2} \mathrm{O}_{2}$. 


\section{RESULTS}

\section{Histology of the gallbladder in the guinea pig and mouse}

In the guinea pig, the walls of the gallbladder consisted of three layers, the mucous membrane, muscular layer and external layer, as revealed by the $\mathrm{HE}$ stained preparations (Fig. 1). The mucous membrane was of two coats, the lining epithelium (a single layer of columnar cells) and lamina propria, whereas any distinct tela submucosa was lacking (Fig. 1). In the lamina propria, relatively abundant blood vessels were involved. The muscular layer was composed primarily of strands of smooth muscle cells intermingled with relatively abundant connective tissue cells and fibers and deserved the name of a fibromuscular coat (Fig. 1). Outside of the muscular layer was situated an external layer of connective tissue natures containing large blood and lymph vessels (Fig. 1).

In the mouse, the walls of the gallbladder were found to be more or less comparable in structural architectures to those in the guinea pig (Fig. 2). The walls consisted of three layers, the mucous membrane, muscular layer and external layer, and each layer contained histological structures which were largely comparable in quality and quantity to those in the guinea pig gallbladder (Fig. 2). In the mouse, however, the gallbladder walls were apparently smaller in thickness than those in the guinea pig, and none of the three layers involved was pronounced in thickness, as compared with that of the guinea pig gallbladder (Fig. 2).

Immunohistochemistry of the gallbladder in the guinea pig

In the gallbladder of the guinea pig, there were relatively few G-I reactive histological structures in the superficial lamina propria and the muscular coat, whereas they were distinct in the deep lamina propria and much more distinguished in amount and reactivity in the external layer (Fig. 3). The epithelium lining the

FIg. 1. Part of the gallbladder in a guinea pig. HE stained. $\times 100$

Fic. 2. Part of the gallbladder in a mouse. HE stained. $\times 200$

Frc. 3. Part of the gallbladder in a guinea pig. Immunoperoxidase for C-I and hematoxylin stained. $\times 100$

Fig. 4. Part of the gallbladder in a guinea pig. Immunoperoxidase for C-III and hematoxylin stained. $\times 100$

Fic. 5. Part of the gallbladder in a guinea pig. Arrows show the positive reaction of the walls of vessels. Immunoperoxidase for C-IV and hematoxylin stained. $\quad \times 200$

Fig. 6. Part of the gallbladder in a guinea pig. Immunoperoxidase for $F$ and hematoxylin stained. $\times 100$

Fig. 7. Part of the gallbladder in a mouse. Immunoperoxidase for C-I and hematoxylin stained. $\times 200$

Fic. 8. Part of the gallbladder in a mouse. Immunoperoxidase for C-III and hematoxylin stained. $\times 200$

Fic. 9. Part of the gallbladder in a mouse. Arrows reveal the positive reaction of the walls of vessels. Immunoperoxidase for C-IV and hematoxylin stained. $\times 200$

Fig. 10. Part of the gallbladder in a mouse. Immunoperoxidase for $F$ and hematoxylin stained. $\times 200$

Fig. 11. Part of the gallbladder in a guinea pig. Control stained (with normal serum) followed by hematoxylin staining. $\times 100$

Fig. 12. Part of the gallbladder in a mouse. Control stained (with buffered saline) followed by hematoxylin staining. $\times 200$ 
Yamada et al.
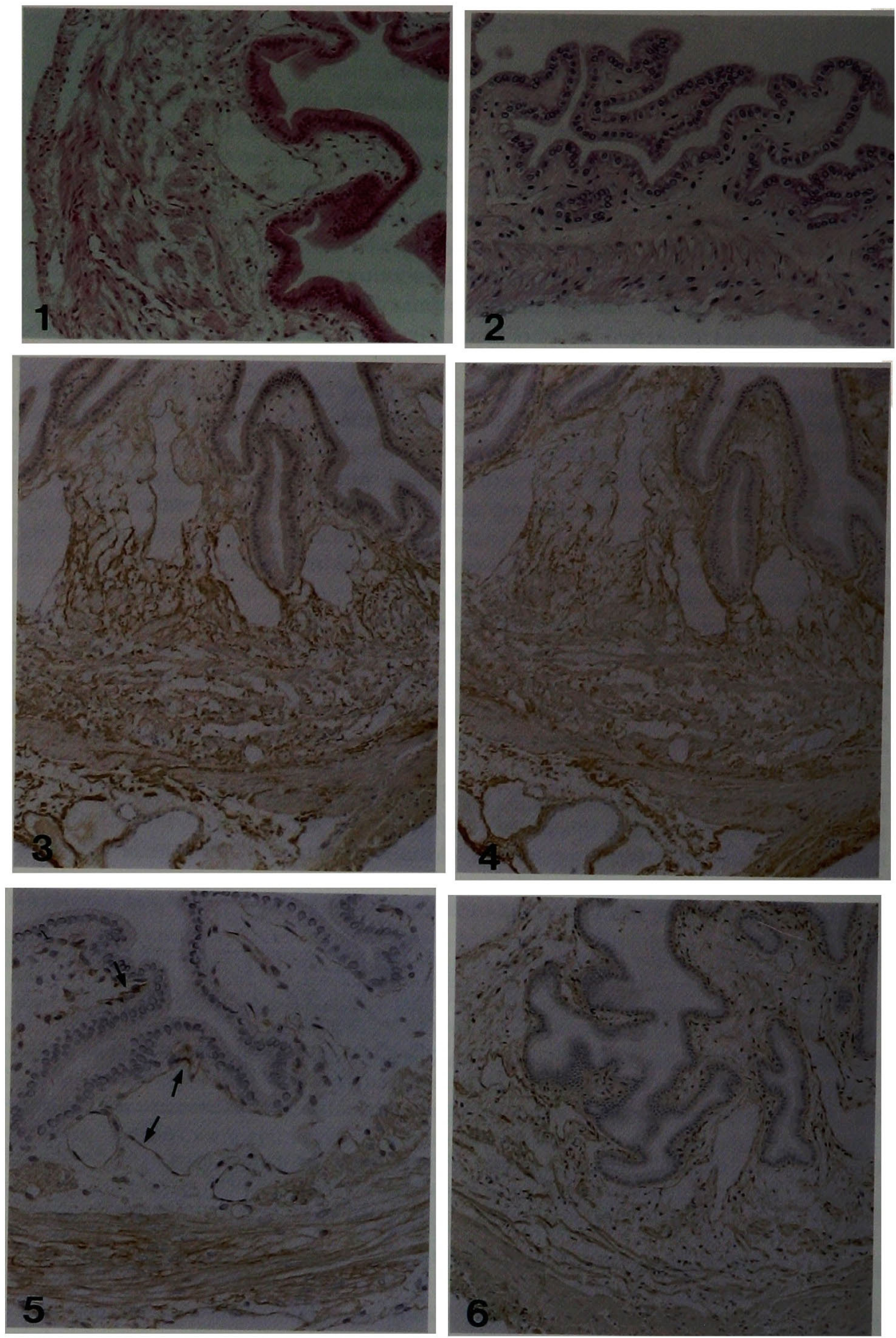

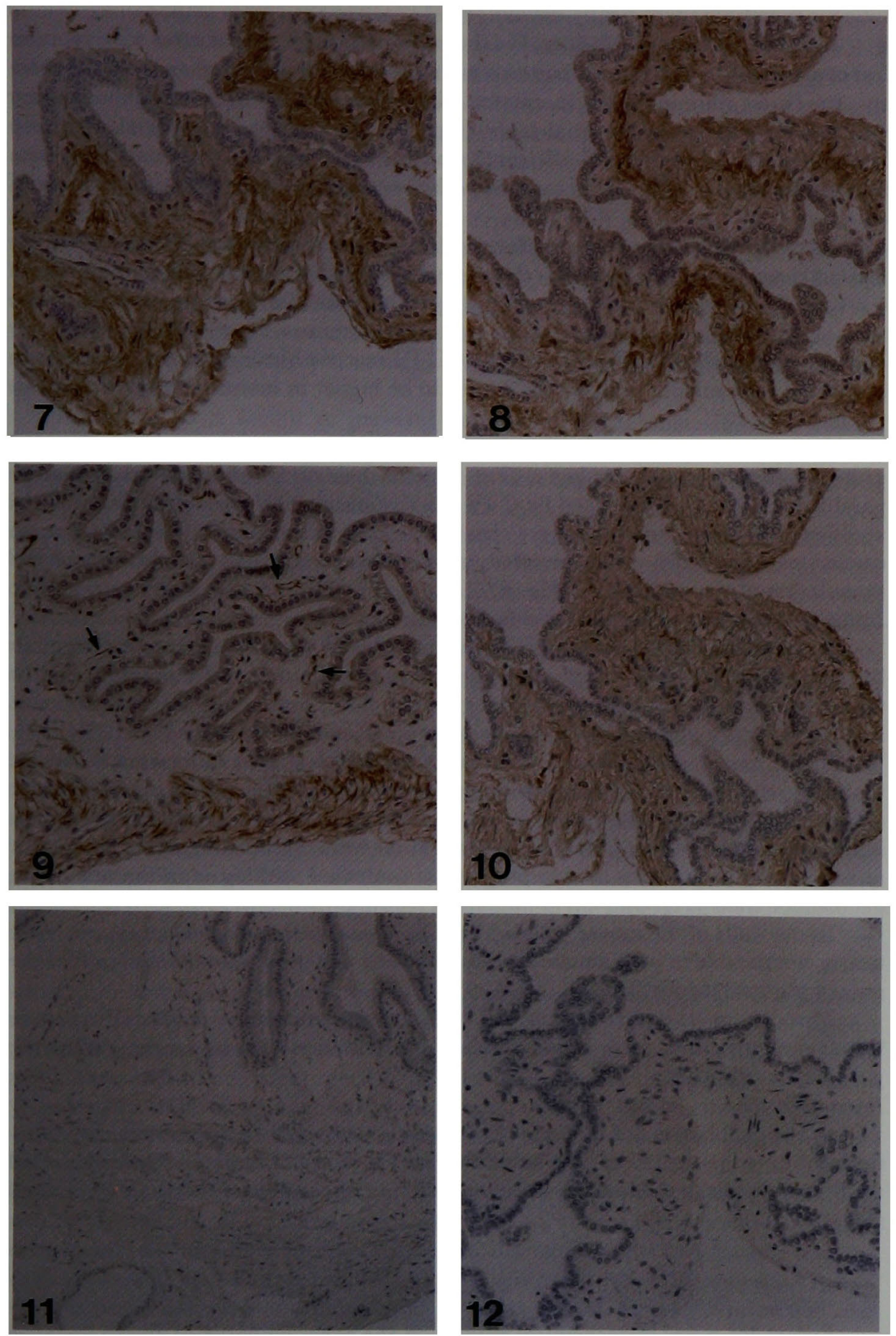
mucous membrane was nearly devoid of C-I reactive structures (Fig. 3).

In the guinea pig gallbladder, G-III reactive histological structures were more or less comparable in distribution patterns to those that were C-I reactive; the C-III reactive structures were indistinct in amount in the muscular layer, whereas the amount was pronounced in the external layer (Fig. 4). In both the superficial and deep laminae propriae, however, C-III reactive histological structures were uniformly pronounced in amount (Fig. 4), in contrast with the corresponding C-I reactive mentioned above.

In the gallbladder of the guinea pig, C-IV reactive histological structures exhibited characteristic localizations throughout all the three layers and were preferentially localized in close association with a series of particular figures such as the basal surface of the lining epithelium of the mucous membrane, blood and lymph vessels and smooth muscle cells (Fig. 5). Of these C-IV reactive histological structures, those associated with smooth muscle cells tended to be higher in intensity of reactions than the rest (Fig. 5).

In the guinea pig gallbladder, $\mathbf{F}$ reactive histological structures were detected rather uniformly in all three layers (Fig. 6), and their distribution pattern was comparable in part to that exhibited by C-IV reactive histological structures (Fig. 6). In addition, $F$ reactive structures were characteristically associated with spindle-shaped connective tissue cells, which revealed variable distribution patterns throughout the three layers of the gallbladder (Fig. 6).

Immunohistochemistry of the gallbladder in the mouse

In the gallbladder of the mouse, C-I reactive histological structures were found to be more or less similar in distribution patterns to those in the guinea pig (Fig. 7). In the mouse, however, C-I reactive histological structures were uniform in both amount and reactivity throughout the deep lamina propria and external layer (Fig. 7).

In the mouse gallbladder, C-III reactive histological structures were, likewise, more or less comparable in distribution patterns to those in the guinea pig gallbladder (Fig. 8). In the mouse, however, the only difference from the corresponding findings in the guinea pig was that $\mathrm{C}$-III reactive structures were most distinguished in amount and reactivity in the deep lamina propria, as campared with those in the rest of the gallbladder walls (Fig. 8).

In the walls of the mouse gallbladder, C-IV reactive histological structures were nearly comparable in both amount and distribution pattern to those in the walls of the guinea pig gallbladder (Fig. 9).

Throughout the three layers of the mouse gallbladder walls, F reactive histological structures were nearly similar in distribution to those in the guinea pig gallbladder (Fig. 10).

Immunohistochemical controls

In the gallbladders of the guinea pig and mouse, none of the control tissue sections subjected to treatment with either the normal serum or buffered saline instead of the first antibodies exhibited any positive reactions for connective tissue antigens at all (Figs. 11, 12).

\section{DISCUSSION}

Except for a few histochemical studies on the pyroninophilia of elastic fibers in 
human gallbladders (19), neutral and acidic glycoproteins and proteoglycans of connective tissue cells, fibers and matrices in mammalian gallbladders (19), cholesterol of subepithelial connective tissues in human gallbladders (2) and IgA, IgM or IgG-containing cells in the mucous connective tissues of normal and inflamed human gallbladders (5), nearly no information has ever been reported as to the histochemistry of connective tissues involved in the mammalian gallbladders. The present results on the immunohistochemistry of connective tissue antigens in the rodent gallbladders appear, therefore to be novel and are to be interpreted with precision. In the present study, the immunohistochemical localizations and properties of C-I, C-III, C-IV and $F$ were found to be common to the two animal species examined, except for a few minor differences between them. Such findings are believed to be evidence that the respective physiological functions of the four connective tissue antigens are largely common to both animal species, perhaps in terms of significant mechanical architectures of the gallbladders.

According to a wealth of previous studies on the biochemistry and related sciences of mammalian and other species connective tissues $(1,6,7,12-18,23,24)$, the four antigens examined in the present study have been recognized in terms of their fundamental properties and physiological activities. The C-I and C-III have been regarded as fibrous proteins of collagenous fibers in general and those of immature collagenous or reticular fibers respectively and as performing histophysiological functions of respective fibers, whereas C-IV has generally been known to be a collagen species of basement membrane type, which is concerned with the control of liquid permeability through the membrane $(6,14,15)$. In addition, $F$ has been recognized as an important glycoprotein which plays important histophysiological roles such as cell and tissue adhesion and integration $(1,16,17,23,24)$, cell extension and motility (7) and basement membrane and fiber formations (7) and cytodifferentiation $(3,11)$. As the present results reveal, C-I reactive histological structures were primarily localized in the deep lamina propria and external layer of the rodent gallbladders. Such localizations are taken to suggest that collagenous fibers provide two mechanical supporting sheets both inside and outside of the muscular layer, which are elements of active contraction and dilatation in the gallbladder. It deserves particular comment that G-III reactive histological structures were distinguished in amount in the superficial viz subepithelial lamina propria of the mucous membrane of the gallbladders. In view of the immature collagenous or reticular fiber natures of C-III $(14,15)$, C-III reactive histological structures in the superficial lamina propria could appropriately be presumed to represent an important structure, which is useful as a mechanical buffer against physical compressions and tensions exerted upon the mucous epithelium (22). In the gallbladders of the two rodent species, the present immunohistochemical localizations of C-IV can well be comprehended by the concept that C-IV represents a fibrous protein involved in basement membranes in general $(14,15)$. Likewise, the present immunohistochemical localizations and properties of $F$ are consistent with certain aspects of its known histophysiological roles recorded above; $F$ is thought to perform such histophysiological functions as cell and tissue adhesion and integration and basement membrane and fiber formations. It, furthermore, apprears probable that the overall distribution of $\mathrm{F}$ throughout the three layers could reflect its important role in cell and tissue adhesion and integration in the course of repeated contraction and dilatation of the walls of the gallbladder. 
As discussed above, some of the results obtained in the present study can reasonably be oomprehended in terms of known physiological functions of the mammalian gallbladders. Further critical histo- and biochemical studies are, however, needed so as to precisely analyze other aspects of the results obtained in the present study.

\section{REFERENCES}

1. Chen, L. B., Mureay, A., Segal, R. A., Rusknell, A. and Walsh, M. L.: Studies on intercellular LETS glycoprotein matrices. Cell 14; 377-391, 1978.

2. English, M. and Hopwood, D.: Lipid in the human gall bladder mucosa. A histochemical study by light and electron microscopy. J. Path. 146; 333-336, 1985.

3. Goldschneider, J. and Moscona, A. A.: Tissue-specific cell-surface antigens in embryonic cells. J. Cell Biol. 53; 435-449, 1972.

4. Graham, R. C. and Karnovsky, M. T.: The early stages of absorption of injected horseradish peroxidase in the proximal tubules of mouse kidney: Ultrastructural cytochemistry by a new technique. J. Histochem. Cytochem. 14; 291-302, 1966.

5. Green, F. H.Y. and Fox, H.: An immunofluorescent study of the distribution of immunoglobulin-containing cells in the normal and the inflamed human gall bladder. Gut 13; 379-384, 1972.

6. Kajikawa, K.: Collagen fibers. In Connective Tissues, Kanahara-Shuppan Publ. Co. Ltd. Tokyo, Osaka, Kyoto, 1984, pp. 131-376 (in Japanese).

7. Kajikawa, K.: Glycoproteins. In Ibid. 1984, pp. 341-365 (in Japanese).

8. Kawaoi, A.: Fundamental techniques of the enzyme-labelled antibody methods. In Histoand Cytochemistry 1980, ed. by Japan Society of Histochemistry and Cytochemistry, Gakusai Kikaku, Tokyo, 1980, pp. 183-201 (in Japanese).

9. Kawaoi, A.: Fundamental principles and techniques of immunohisto- and cytochemistry. In Histo- and Cytochemistry 1983, ed. by Japan Society of Histochemistry and Cytochemistry, Gakusai Kikaku. Tokyo, 1983, pp. 55-78 (in Japanese).

10. Koga, A.: Gallbladder. In Human Histology 4. Digestive Organs ed. by K. Ogawa et al., Asakura-Shoten. Tokyo, 1987, pp. 435-445 (in Japanese).

11. Linder, E., Vaheri, A., Ruoslahti, E. and Wartiovaara, J.: Distribution of fibroblast surface antigen in the developing chick embryo. J. Exp. Med. 142; 41-49, 1975.

12. Miller, E. J.: A review of biochemical studies on genetically distinct collagens of the skeletal system. Clin. Orthop. 92; 260-280, 1973.

13. Miller, E. J.: Biochemical characteristics and biochemical significance of the genetically distinct collagens. Mol. Cell Biochem. 13; 165-190, 1976.

14. Nagai, Y.: Biochemistry of connective tissues.-Biochemistry, chemical structure, metabolism-General statement. Jap. J. Clin. Med. 42; 11-19, 1984 (in Japanese).

15. Ohdaka, Y.: Biochemistry of connective tissues. In Connective Tissue Diseases-New Concept and Pathology, Kanahara-Shuppan Publ. Co. Ltd. Tokyo, Osaka, Kyoto, 1984, pp. 67-80 (in Japanese).

16. Pearlstein, E., Gold, L. I. and Garcia-Pardo, A.: Fibronectin: A review of its structure and biological activity. Mol. Cell Biochem. 29; 103-128, 1980.

17. Ruoslahti, E., Engvall, E. and Hayman, E.: Fibronectin: current concepts of its structure and function. Collagen Res. 1; 95-128, 1981.

18. Trelstad, R. L.: The developmental biology of vertebrate collagens. J. Histochem. Cytochem. 21; 521-528, 1973.

19. Wallraff, J.: Gallenblase und Gallenwege. In Handbuch der mikroskopischen Anatomie des Menschen, ed. by W. v. Möllendorff u. W. Bargmann, 5ter Bd, 4ter Teil, Springer-Verlag. Berlin, Heidelberg, New York, 1969, ss. 292-346. 
20. Yamada, K.: Development and differentiation of connective tissues. Jap. J. Clin. Med. 42; 410,1984 (in Japanese).

21. Yamada, K.: Detection of tissue antigens (Immunohistochemistry). In Histochemistry. Fundamentals and Practices for Beginners, Nanko-Do, Tokyo, Kyoto, 1987, pp. 389-431 (in Japanese).

22. Yamada, K. and Fujimori, O.: Histochemistry of the gall bladder-epithelial carbohydrates and connective tissue antigens. Acta Anat. Nippon 63; 294, 1988 (in Japanese).

23. Yamada, K. M. and Kenneth, O.: Fibronectin-adhesive glycoproteins of cell surface and blood. Nature 275; 179-184, 1978.

24. Yamada, K. M., Olden, K. and Pastan, I.: Transformation-sensitive cell surface protein: Isolation, characterization and role in cellular morphology and adhesion. Ann. N. Y. Acad. Sci. 312; 256-277, 1978. 